\title{
LABORATÓRIO DE SISTEMAS DIGITAIS REMOTO: UMA EXPERIÊNCIA EM TEMPOS DE PANDEMIA DO SARS-COV-2
}

DOI: 10.37702/2175-957X.COBENGE.2021.3447

Kechi Hirama - kechi.hirama@usp.br

Universidade de São Paulo

Avenida Professor Luciano Gualberto travessa 3

04087-002 - São Paulo - SP

Resumo: A pandemia do novo coronavirus, o Sar-Cov-2, declarada oficialmente em 11 de março de 2020 pela Organização Mundial de Saúde (OMS) fez com que muitas atividades, entre outras, na educação tivessem que ser interrompidas. Para não comprometer o período letivo, muitas atividades precisavam ser retomadas no modo remoto e para isso muitas ferramentas baseadas em Internet foram propostas e usadas com sucesso. O curso de Engenharia Elétrica da Escola Politécnica da Universidade de São Paulo fez suas adaptações, porém o desafio estava nas disciplinas de laboratório. Este trabalho tem por objetivo apresentar as soluções encontradas para a disciplina de Laboratório Digital do Departamento de Engenharia de Computação e Sistemas Digitais (PCS). O resultado observado e manifestado por professores e alunos foi de que a disciplina cumpriu seu papel e com pequena perda de desempenho se comparado ao modo presencial.

Palavras-chave: Ensino remoto, laboratório digital remoto, ferramentas de software 


\section{LABORATÓRIO DE SISTEMAS DIGITAIS REMOTO: UMA EXPERIÊNCIA EM TEMPOS DE PANDEMIA DO SARS-COV-2}

\section{INTRODUÇÃO}

A pandemia do novo coronavírus, o Sars-Cov-2, foi declarada mundialmente pela Organização Mundial de Saúde (OMS) no dia 11 de março de 2020. Desde então, a doença Covid-19 provocada pelo vírus atingiu o Brasil e em 13 de março de 2020, muitas atividades do dia-a-dia, escritórios, escolas e universidades interromperam as suas atividades e, enquanto aguardava-se a possível retomada das atividades presenciais, a pandemia somente cresceu. As pessoas tiveram que estabelecer um isolamento social e muitas atividades foram transferidas dos seus locais originais de trabalho para seus lares (home office).

Particularmente, no Departamento de Engenharia de Computação e Sistemas Digitais (PCS) da Escola Politécnica da Universidade de São Paulo, as atividades didáticas tiveram que ser adaptadas para atividades remotas para não comprometer o primeiro semestre que iniciou em 17 de fevereiro de 2020.

As disciplinas de laboratório têm por objetivo a prática de conceitos e as atividades de manipulação de processos físicos e materiais, diferentemente das disciplinas teóricas, tiveram que fazer várias adaptações para que a ementa da disciplina fosse minimamente cumprida com atividades remotas.

A experiência relatada neste trabalho foi desenvolvida no Laboratório de Sistemas Digitais do PCS para alunos do $3^{\circ}$. ano (5ㅜ. semestre) do curso de Engenharia Elétrica de março de 2020 a fevereiro de 2021.

\section{TRABALHOS RELACIONADOS}

Dentro das mais modernas formas de ensino apoiadas no desenvolvimento do computador e da Internet tem se o ensino remoto, online ou à distância. Essas formas têm sido aplicadas há um bom tempo, mas a pandemia do novo Coronavirus obrigou de um dia para outro que o ensino de maneira geral em todos os níveis, sobretudo no nível superior, buscasse rapidamente uma mudança do modo presencial para formas virtuais para não comprometer o ano letivo.

$\mathrm{Na}$ literatura, devido à pandemia iniciada em 2020, muitas experiências no campo do ensino de várias disciplinas têm sido publicadas tais como Sari et al (2020), Gamage et al (2020), Bekasiewicz et al (2020), Delgado et al (2021), Sherrer (2020), Serafin \& Chabra (2020), Maladzhi \& Kanakana-Katumba (2020), Syah et al (2020) A seguir, são discutidos os trabalhos mais relevantes entre estas publicações.

O trabalho de Sari et al (2020) mostra um estudo de como os estudantes de $2^{\circ}$. Grau foram conduzidos a terem aulas à distância, dentro do programa de governo da Indonésia, para proteger os estudantes da Coronavirus. O estudo de Sari et al (2020) abrangeu como as aulas de Química foram dadas no formato online, quais ferramentas foram usadas, como as atividades de laboratório de Química foram realizadas e qual foi o aprendizado alcançado com a aulas à distância pelos estudantes. Uma enquete foi realizada e o que se apurou foi que as aulas teóricas foram bem conduzidas, porém as atividades de laboratório foram realizadas por apenas $18 \%$ dos estudantes que usaram materiais encontrados facilmente em suas casas. $O$ índice destas atividades foi baixo, pois no caso de Química, é muito difícil realizar as experiências propostas fora do laboratório. Outro dado importante é que $74,3 \%$ dos estudantes tiveram problemas para 
frequentar e ter bom aproveitamento das aulas devido a problemas de instabilidade de conexão de Internet e, também, não tinham suporte no momento que eles tinham dúvidas sobre as atividades a serem realizadas. Assim, 92,8\% preferiram as aulas no modo presencial (fase-a-face).

O trabalho de Gamage et al (2020) apresenta uma revisão de esforços empreendidos por universidades em realizar atividades remotas e práticas de laboratório, antes e durante a pandemia considerando a experiência vivida pelos estudantes, seu aprendizado e bem-estar. Um dos resultados dessa revisão foi que em um curso de Engenharia Elétrica na Korea quebrou o formato de trabalho experimental tradicional de laboratório reservado a espaços pré-definidos para ambientes colaborativos de aprendizado entre professores e alunos no formato online. Outro resultado foi relacionado a 160 experimentos com simulações, experiências virtuais ou controle remoto de experiências oferecidas por uma universidade na China que cobriram disciplinas tais como Química, Física, Circuitos Elétricos, Máquinas Elétricas, Engenharia Mecânica, Redes de Computadores, etc. Eles apontaram desafios em trabalhos online, sobretudo considerando trabalho experimental no currículo de engenharia que aponta em alto nível desenvolvimento de capacidades de análise e resolução de problemas, projeto, familiarização com materiais e equipamentos, comunicação e relacionamento interpessoal, julgamento técnico e prática profissional, integração de teoria e prática e motivação de estudantes. Porém, a oportunidade de trabalhos colaborativos que as práticas de laboratório online trouxeram pode aumentar a efetividade do ensino e melhorando a capacidade de realizar atividades em equipe para atingir objetivos em cooperação e integrar o conhecimento de outros em realizar uma dada tarefa.

Outro trabalho interessante é o de Bekasiewicz et al (2020) que discute a transição do ensino de laboratório de hardware tradicional para o ensino remoto. Eles introduziram uma infraestrutura para aulas de laboratório de FPGA (Field Programmable Gate Array) que são dispositivos programáveis de hardware que tem diversas aplicações tais como nas áreas médica, aeroespacial, indústria, etc. Essa infraestrutura é inadequada, pois não há soluções prontas e não se encontram facilmente componentes no mercado. Porém, a ideia é complementar o modelo tradicional e aumentar a participação dos estudantes nos cursos. Apesar disso, Bekasiewicz et al (2020) consideram que o desenvolvimento de um sistema fim-a-fim que apoie o conceito de aprender na prática em ambiente totalmente remoto é um problema em aberto. Eles apresentaram uma proposta de um laboratório de FPGA de baixo custo. Algumas premissas definidas para este laboratório foram: disponibilidade $24 / 7$ das bancadas; avaliação heterogênea das placas de FPGA; experiências de FPGA para o nível de graduação; acesso remoto para todos os pacotes de software; fácil configuração das bancadas e mecanismo simples de feedback para observação do comportamento das placas. Nesse ambiente, os estudantes conectam seus computadores, dispositivos móveis, etc. ao servidor (laboratório de FPGA) da universidade para realizar as experiências. Ao fim das experiências, os estudantes submetem seus relatórios e recebem uma nota. Foi realizada uma enquete com os estudantes e os autores obtiveram como resposta uma grande satisfação dos estudantes quanto aos aspectos técnicos do trabalho remoto e também, sobre a qualidade da documentação. As configurações das bancadas remotas e a sua disponibilidade 24/7 receberam as maiores notas dos estudantes.

O trabalho de Delgado et al (2021) apresenta um caso de uma plataforma usada no curso virtual de Elementos de Mecatrônica. Algumas ferramentas de software de simulação usadas na plataforma foram FluidSim, Factory $1 / O$, Tinkercad e Overleaf de custo zero. Elas propiciaram excelentes interações entre os estudantes e a plataforma e uma experiência satisfatória entre os professores e os estudantes. Os professores 
realizaram uma avaliação de desempenho comparando o curso em 2018 e 2020 (antes e com a pandemia). Os resultados mostraram que o desempenho acadêmico dos estudantes não foi afetado pela pandemia. Por outro lado, os estudantes manifestaram satisfação com o esforço dos professores em mudar para o modo online e, também, com os tipos de atividades desenvolvidas por cada atividade prática do laboratório virtual.

\section{LABORATÓRIO DIGITAL}

O programa da disciplina PCS3335 - Laboratório Digital A pode ser resumido em: Experiências práticas sobre projeto e implementação de sistemas digitais, incluindo aspectos de interfaces com sistemas analógicos. Aplicação da metodologia de projeto estruturado na implementação de sistemas digitais com lógica programável. Blocos combinatórios: portas lógicas, multiplexadores, decodificadores, somadores e unidades lógicas e aritméticas (ULAs). Blocos sequenciais: flip-flops, registradores, deslocadores, contadores. Máquinas de estado. Memórias. Uso de linguagens de descrição de hardware. Introdução a ferramentas de projeto e simulação de sistemas digitais (Júpiter, 2019).

No ano de 2020 participaram aproximadamente 180 alunos divididos em 12 turmas entre 8 professores, 2 técnicos e 2 monitores. Os alunos foram divididos em grupos de 2 sendo possível alocá-los em 16 bancadas por meio-período do dia. A Figura 1 apresenta uma dessas bancadas onde se destacam o painel de montagens de circuitos, FPGA, fontes de alimentação, osciloscópio, gerador de funções e computador desktop.

Figura 1 - Bancada típica do PCS3335.

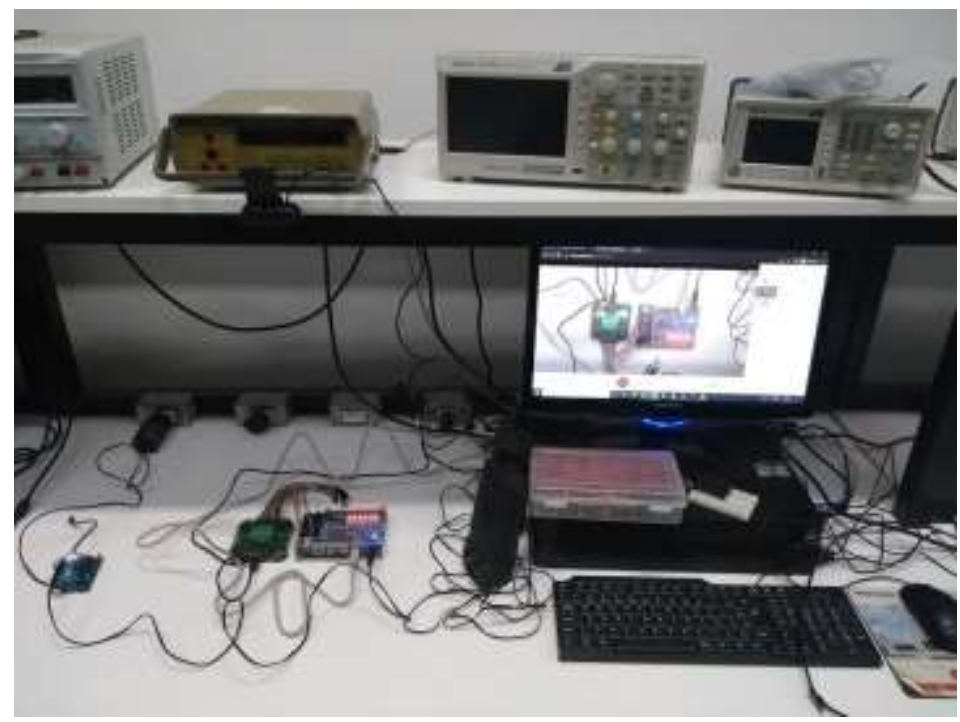

Fonte: PCS (2021).

Uma experiência é planejada pelos alunos com antecedência e é montada e testada durante as aulas. Os resultados são colocados em um relatório entregue pelos alunos no fim da aula. A disciplina PCS3335 tem 3 créditos aula ou 150 minutos de duração. 


\subsection{Plataformas, dispositivos e aplicativos usados}

A disciplina PCS3335 usa duas plataformas para gerenciamento das atividades, o Google Drive como repositório dos docentes e e-Disciplinas (baseado no Moodle) como repositório dos professores para comunicar avisos aos alunos e lançar novos enunciados de experiências e dos alunos para submeterem seus trabalhos. O e-Disciplinas possui, entre outros, mecanismos para definir um prazo para as atividades.

Como aplicativos de projeto, usa-se o Digital para modelagem e simulação de circuitos digitais e o Quartus para modelagem, simulação e programação de dispositivos FPGA da Altera. Os aplicativos rodam em computadores tanto dos alunos como também nos computadores das bancadas do laboratório. Usa-se também o aplicativo Google Meet para as aulas remotas.

\subsection{Aplicativo Digital}

A Figura 2 apresenta uma tela típica do aplicativo Digital.

Figura 2 - Tela típica do Digital.

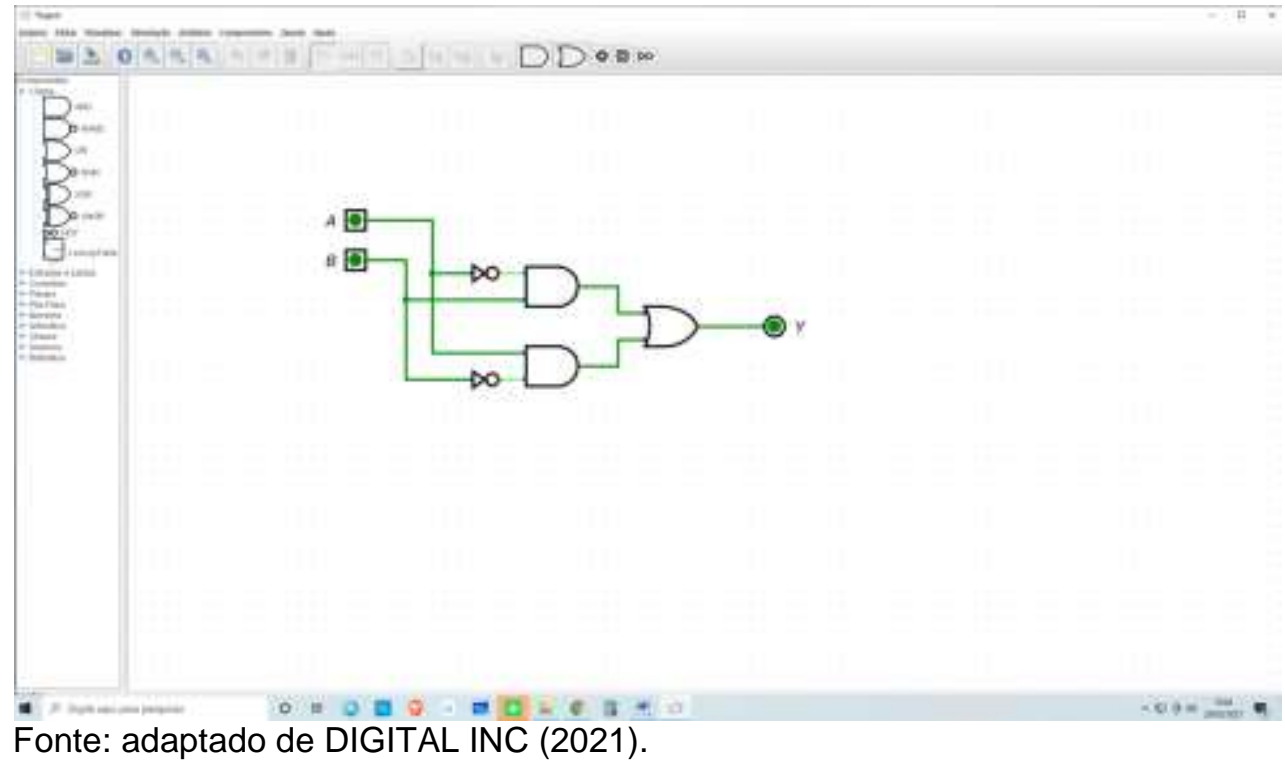

\subsection{Aplicativo Quartus}

A Figura 3 apresenta uma tela típica do aplicativo Quartus. 
Figura 3 - Tela típica do Quartus.

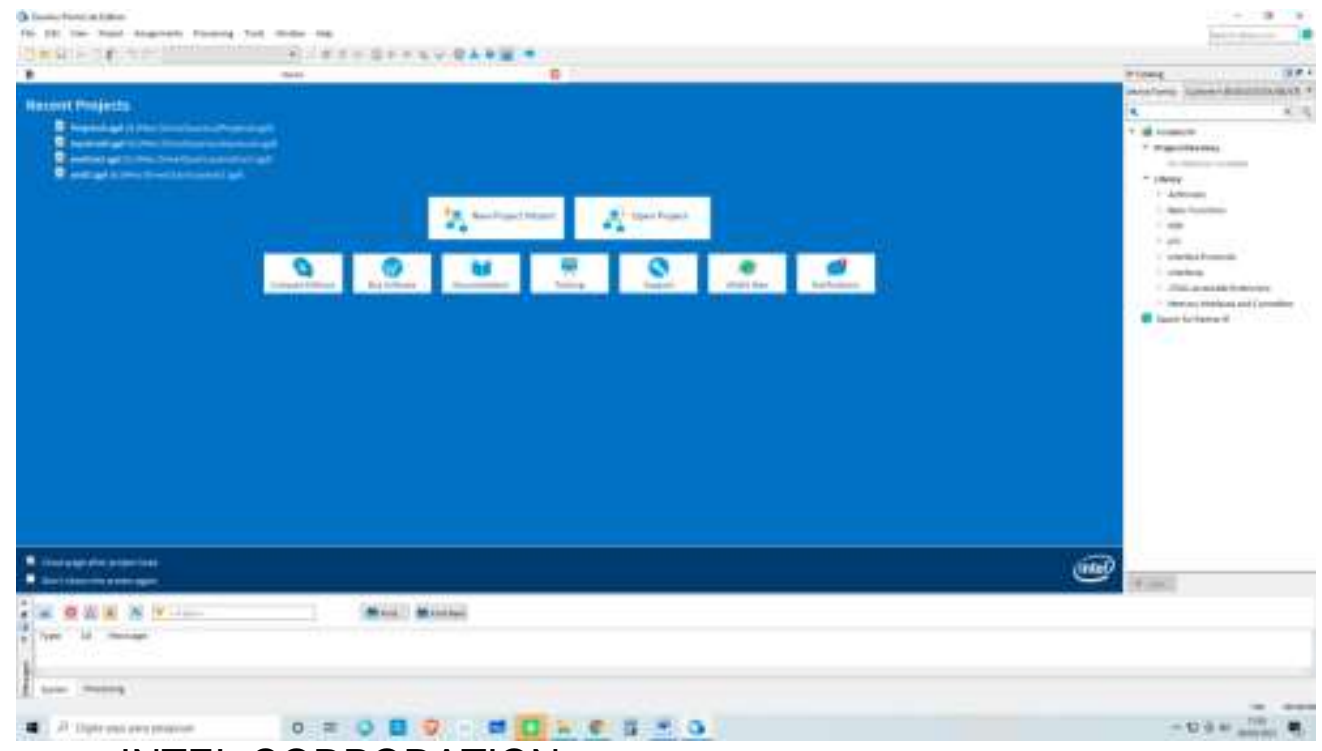

Fonte: INTEL CORPORATION (2021).

\subsection{Dispositivo FPGA}

- O FPGA (Field Programmable Gate Array) é um dispositivo lógico programável que permite a implementação de diversos circuitos digitais. A placa FPGA DE0-CV da Altera (Figura 4) é uma plataforma de hardware robusta que permite desenvolver circuitos com alto desempenho, baixo custo e baixo consumo de energia.

Figura 4 - Placa de PGA DE0-CV da Altera.

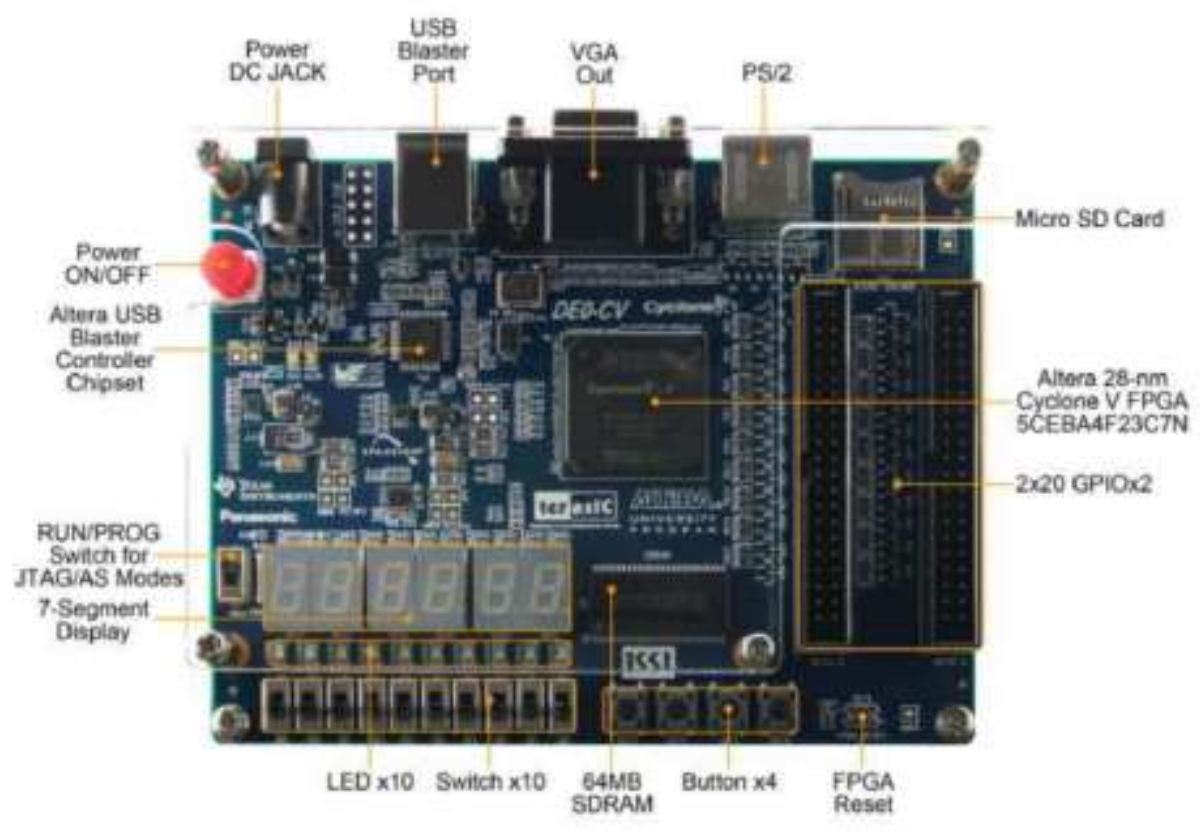

Fonte: TERASIC INC (2016). 


\subsection{Dispositivo Analog Discovery}

O Analog Discovery é dispositivo multifuncional que tem, entre outras, a função de um osciloscópio e um analisador lógico que permite medir, visualizar, gerar, registrar e controlar sinais de circuitos de todos os tipos. A Figura 5 apresenta o dispositivo da Digilent.

Figura 5 - Analog Discovery 2 da Digilent.

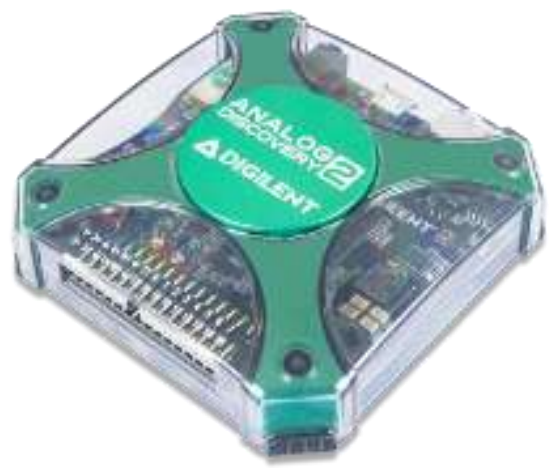

Fonte: DIGILENT INC (2021).

\subsection{Bancada remota do Laboratório Digital}

Uma bancada remota do Laboratório Digital é constituída de um computador, uma placa FPGA, uma placa Analog Discovery e uma câmera. Estes equipamentos estão conectados ao computador via USB (Figura 7).

Figura 7 - Bancada remota do Laboratório Digital.

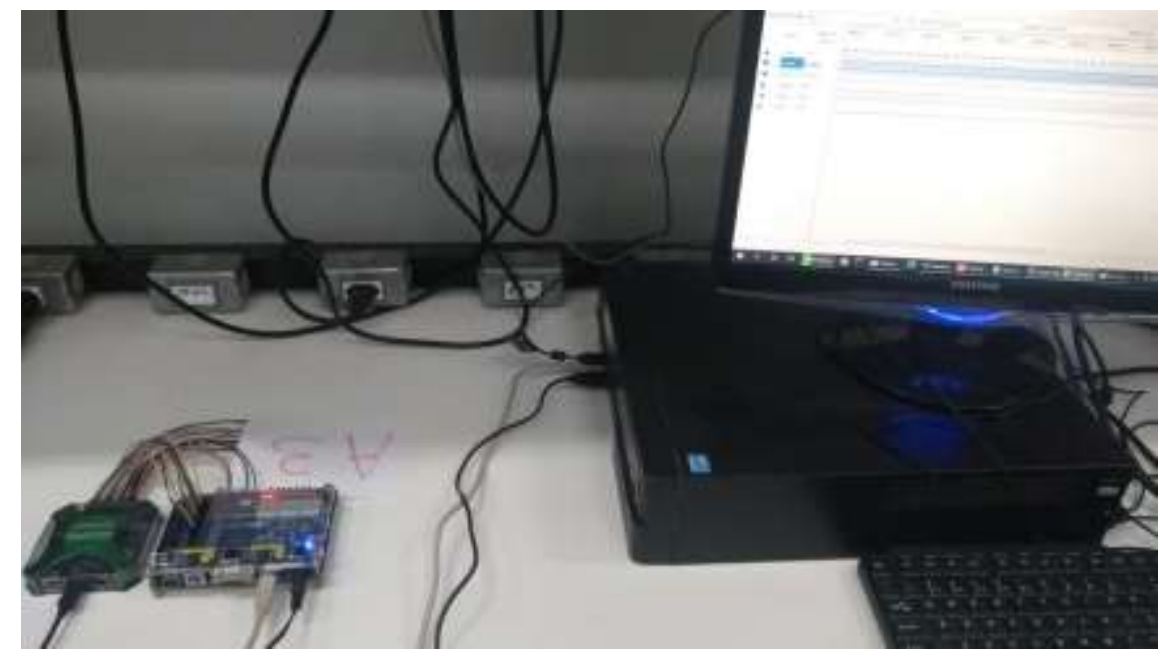

Fonte: PCS (2021).

A ideia é permitir que um aluno pudesse acessar remotamente a bancada, carregar um circuito no FPGA e realizar testes e observar o seu funcionamento com o Analog Discovery pela câmera.

Para isto, o dispositivo possui um software chamado WaveForms, já instalado, que possibilita o uso de instrumentos analógicos e digitais. A Figura 8 apresenta a tela inicial do WaveForms onde se destacam as várias opções de uso do dispositivo. A opção Scope permite usar canais do osciloscópio (Figura 9) para observar sinais analógicos ou formas 
de onda digitais e a opção Static I/O permite usar sinais digitais de entrada e de saída (Figura 10) do FPGA.

Figura 8 - Tela Inicial do WaveForms.

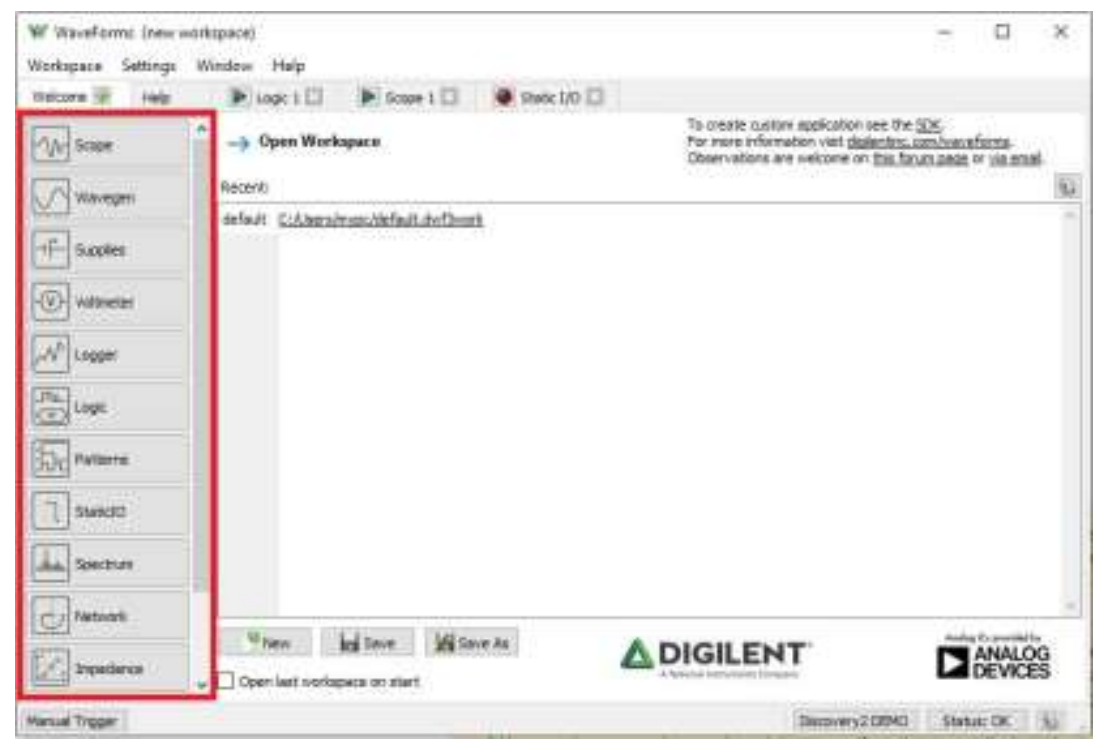

Fonte: DIGILENT INC (2021).

Figura 9 - Tela opção Scope para Osciloscópio.

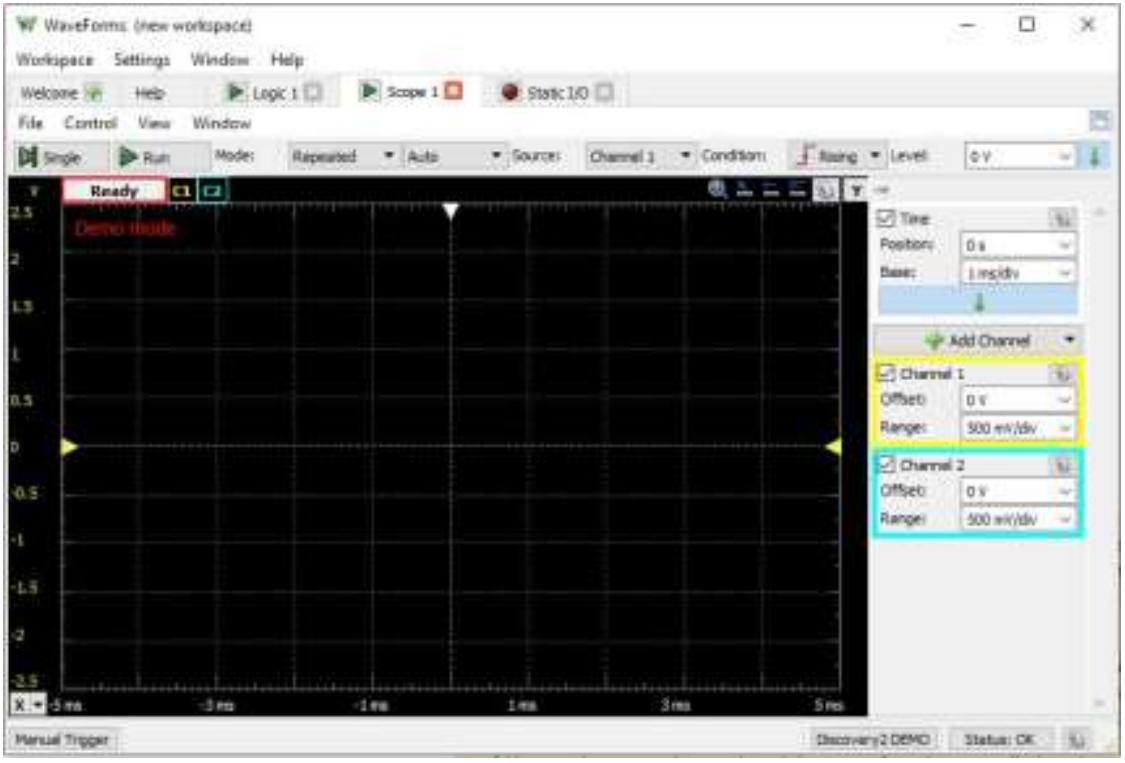

Fonte: DIGILENT INC (2021). 
Figura 10 - Tela opção Static I/O para sinais digitais.

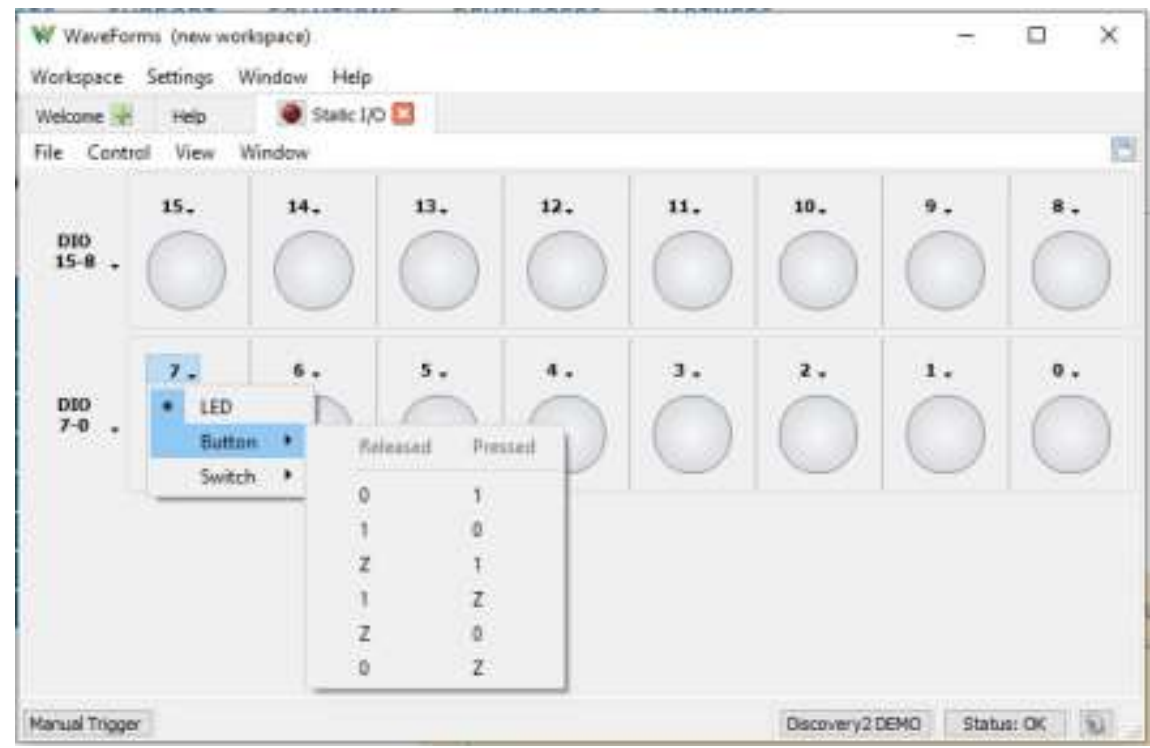

Fonte: DIGILENT INC (2021).

\section{LABORATÓRIO DIGITAL REMOTO}

Com o início da pandemia do Sars-Cov-2, os cursos precisavam dar continuidade às suas atividades no modo remoto. Como se sabe, os responsáveis pelas disciplinas que tem um caráter de laboratório, sobretudo nos cursos de Engenharia, onde a prática é essencial para complementação do aprendizado teórico, tiveram que procurar alternativas para tornar o laboratório viável e factível no modo remoto, ou seja, as experiências deviam ser executadas sem a presença física dos alunos nas bancadas das experiências. Usar equipamentos e obter medidas dos experimentos feitas por grupos de alunos que se interagem durante as experiências são cenários de difícil reprodução no modo remoto.

Figura 11 - Arranjo do Laboratório Digital remoto.

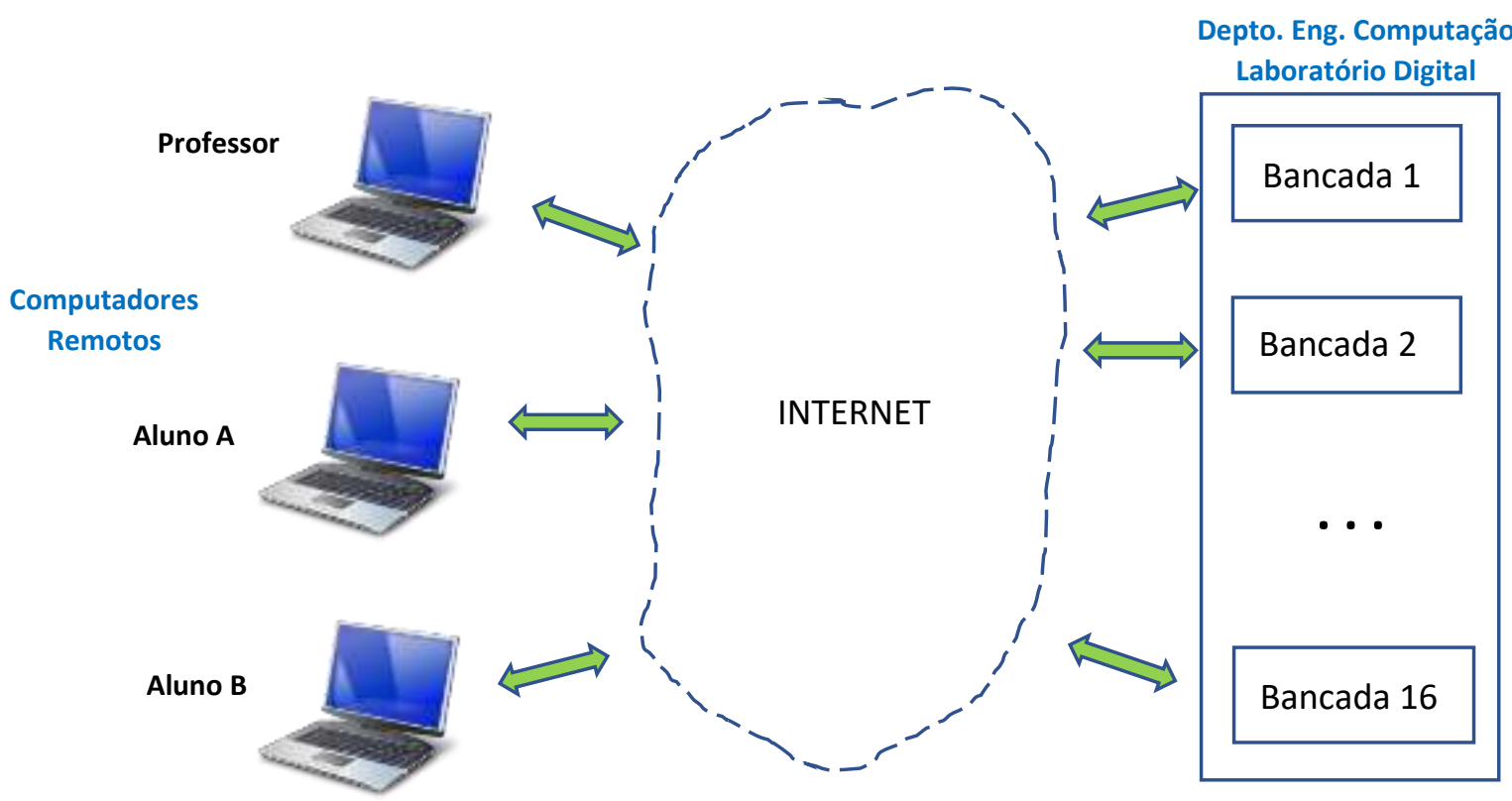

Fonte: Autor. 
Essas alternativas surgiram ao longo do ano de 2020 baseadas em ferramentas de Internet, que tinham como requisitos, serem baratas, acessíveis e de fácil aprendizado pelos alunos. A Figura 11 mostra o arranjo do laboratório digital remoto desenvolvido na disciplina PCS3335 - Laboratório Digital A para os alunos do 6‥ Semestre do curso de Engenharia Elétrica.

A Figura 7 apresentada anteriormente é uma das bancadas organizadas para as experiências com FPGA. Os itens físicos dessa bancada são: um computador, uma placa FPGA DE0-CV da Altera, um Analog Discovery 2 da Digilent.

Este arranjo conta com o aplicativo AnyDesk e Câmeras para visualizar as experiências realizadas nas bancadas do laboratório digital.

O AnyDesk é um software que permite o acessos remoto a outro computador e ter o controle sobre ele. O software é multiplataforma disponível para Windows, Linux, Mac, Android etc.

A Figura 12 apresenta uma tela típica do aplicativo AnyDesk.

Figura 12 - Tela típica do AnyDesk.

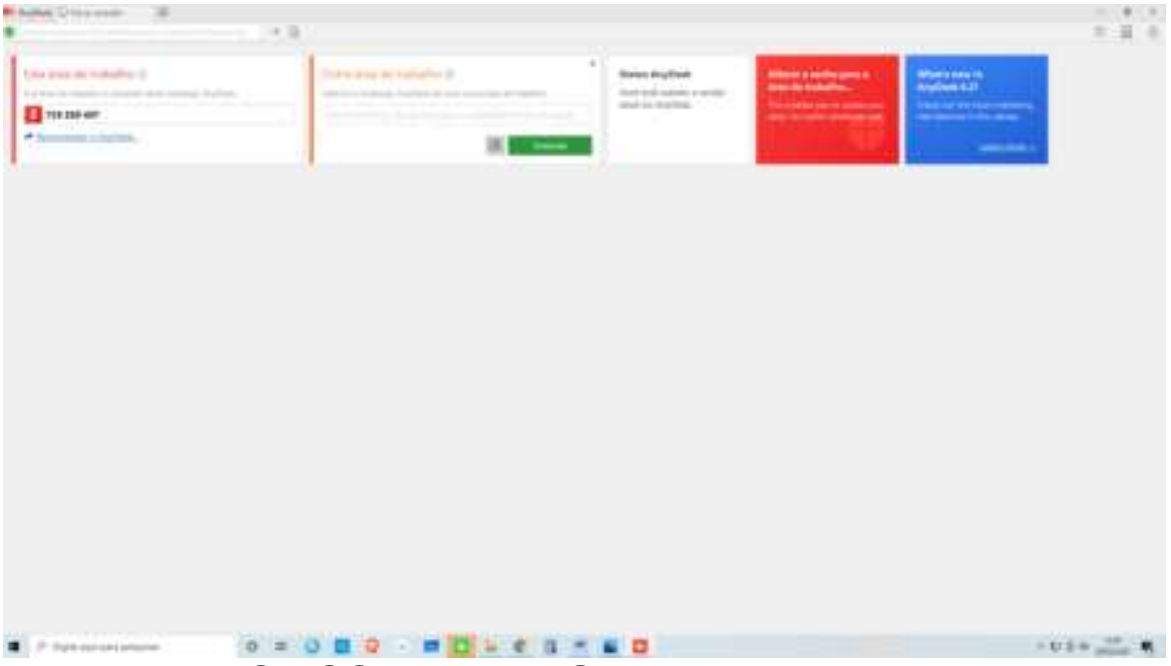

Fonte: ANYDESK SOFTWARE GMBH (2021).

Após login e senha (ou com a permissão do computador da bancada), o aluno pode usar todas as ferramentas existentes no computador da bancada física. A área de trabalho do AnyDesk do aluno é substituída pela área de trabalho do computador da bancada.

O professor da disciplina que também está remoto pode acompanhar o que o aluno está desenvolvendo no seu computador e também na bancada. Existem duas maneiras de fazer esse acompanhamento. A primeira é fazer o mesmo processo do aluno e usando - AnyDesk de sua máquina ter para si a mesma tela do computador da bancada podendo acompanhar todas as ações do aluno. A segunda é usando uma ferramenta de comunicação por vídeo, no caso o Google Meet. O aluno pode compartilhar a sua tela que por sua vez está ligada à tela do computador da bancada.

\section{REALIZAÇÃO DE UMA EXPERIÊNCIA}

O enunciado de uma experiência é publicado na plataforma e-Disciplinas que é um ambiente virtual de apoio à graduação e pós-graduação da USP. A partir do enunciado publicado com uma semana de antecedência os alunos organizados em grupos com 2 
membros devem elaborar um planejamento da experiência que deve ser entregue 24 horas antes da sua realização.

No dia da experiência, os alunos são colocados em salas de trabalho no Google Meet e, em seguida, o professor esclarece alguns erros cometidos ou dúvidas do planejamento para iniciar a implementação das soluções seguida de demonstrações do seu funcionamento. Neste caso, a ferramenta usada é o Digital para a parte combinatória e Quartus para gravar a FPGA da bancada para a parte sequencial do circuito. A monitoração pode ser feita na própria montagem do FPGA visto por câmeras ou com 0 uso do aplicativo Waveforms do dispositivo Analog Discovery.

Após a parte planejada seja realizada, o professor solicita a realização de um desafio ligado ao tema da experiência.

No fim, os alunos devem entregar o relatório do grupo na plataforma e-Disciplinas com prazo de 6 horas.

\section{DISCUSSÃO}

O início da pandemia fez com que de repente, já com as aulas iniciadas, todo o planejamento de uma disciplina necessitasse de adaptações urgentes para não comprometer o semestre/ano letivo. Essas adaptações levavam em conta ainda o uso de ferramentas de reuniões/aulas remotas (Zoom, Google Meet e outras) onde professores e alunos pudessem interagir. Proporcionalmente, as disciplinas ditas teóricas (com aulas expositivas) tiveram uma adaptação mais suave. Os materiais de aula precisaram ser, pelo menos, digitalizadas. Aquelas ditas práticas (laboratórios) tiveram que pensar como poderiam aplicar as atividades sem a manipulação direta de componentes físicos necessários para montar, executar e tirar dados das experiências.

No caso da disciplina PC3335 - Laboratório Digital A discutida neste trabalho, a configuração de 12 turmas, 8 professores, 2 monitores e 2 técnicos, além de todo o planejamento da disciplina ter sido feito para o modo presencial, foi um desafio muito grande. Em primeiro lugar, foi realizada uma reunião logo depois de o isolamento social ter sido decretado em meados de março de 2020. A premissa era manter a ementa da disciplina neste novo cenário. $O$ consenso foi que a disciplina fosse minimamente mantida com atividades remotas tais como planejamento das experiências (já era uma atividade a ser feita fora das aulas e recebida via repositório do e-Disciplinas). A parte de execução foi realizada para um conjunto de experiências consideradas essenciais com o uso de ferramentas de software tais como o Digital/Logisim e Multisim, Anydesk e Waverforms.

Todo esse novo planejamento foi realizado com sucesso, em meio às perspectivas de retorno às atividades presenciais no $2^{\circ}$. Semestre de 2020. Assim, somente a segunda prova prevista para junho de 2020 , que era prevista como presencial no planejamento foi realizada no modo remoto somente em fevereiro de 2021.

\section{$7 \quad$ CONCLUSÕES}

A experiência relatada neste trabalho foi fruto de muita coesão e engajamento por parte dos envolvidos, professores, alunos, monitores e técnicos. O reconhecimento das dificuldades, principalmente, da parte dos alunos fez com que até computadores e acesso à Internet fossem providenciados pela Escola Politécnica da Universidade de São Paulo para minimizar os impactos nas aulas remotas. 
Este ano, a disciplina foi iniciada em 12 de abril de 2021 novamente com 12 turmas. A experiência vivida em 2020 está sendo muito útil para se acreditar no sucesso em 2021.

Como trabalhos futuros, novas ferramentas estão sendo pesquisadas para minimizar a distância entre o laboratório presencial e o remoto, como foi dito anteriormente, no modo remoto perde-se um aspecto importante do laboratório presencial que é o contato físico e a vivência com equipamentos, dispositivos, componentes em ambientes reais que muitas vezes influenciam os resultados das experiências.

\section{Agradecimentos}

Agradeço aos professores, alunos, monitores e técnicos da disciplina PCS3335 Laboratório Digital A (2020) onde os seus feedbacks durante a realização da disciplina ajudaram muito nas correções de rumo durante a pandemia. Em especial, agradeço ao colega Prof. Dr. Edson Toshimi Midorikawa, coordenador da disciplina análoga do curso de Engenharia de Computação da Escola Politécnica da USP, que compartilhou seus conhecimentos para que a disciplina PCS3335 tivesse o sucesso que alcançou.

\section{REFERÊNCIAS}

ANYDESK SOFTWARE GMBH. Remote Desktop Application. Germany. 2021. Disponivel em: https://anydesk.com/pt. Acesso em: 08 abr. 2021.

BEKASIEWICZ, A. et al. Application of Open-Hardware-Based Solutions for Rapid Transition From Stationary to the Remote Teaching Model During Pandemic. IEEE Transactions on Education, p. 1-9. 2020. Disponível em: https://doi.org/10.1109/te.2020.3043479. Acesso em: 03 fev. 2021.

DELGADO, L. D. R. et al. Mechatronics Teaching through Virtual Platforms for Home Confinement due to COVID-19. In: International Conference on Mechatronics, Electronics and Automotive Engineering (ICMEAE). Proceedings. Cuernavaca, México. 2020. Disponível em: https://doi.org/10.1109/ICMEAE51770.2020.00038. Acesso em: 08 fev. 2021.

DIGILENT INC. Analog Discovery 2. USA. 2021. Disponível em:

https://reference.digilentinc.com/reference/instrumentation/analog-discovery-2/start.

Acesso em: 08 abr. 2021.

GAMAGE, K. A. A. et al. Online Delivery of Teaching and Laboratory Practices: Continuity of University Programmes during COVID-19 Pandemic. Education Sciences. v. 10, i. 10, 2020. Disponível em: https://doi.org/10.3390/educsci10100291. Acesso em: 08 fev. 2021.

INTEL CORPORATION. Intel FPGA Development Tools. Disponível em : https://www.intel.com.br/content/www/br/pt/software/programmable/quartusprime/download.html. Acessoa em 08 abr. 2021.

MALADZHI, R. W.; KANAKANA-KATUMBA, G. M. Evolution of Teaching Approaches for Science, Engineering and Technology within na Online Environment: A Review. Advances in Science, Technology and Engineering Systems Journal. v. 5, n. 6, p. 
1207-1216. 2020. Disponível em: https://dx.doi.org/10.25046/aj0506144. Acesso em: 03 fev. 2021.

PCS. Fotos do Laboratório Digital. Repositório do PCS. 2021.

SARI, I. et al. Chemistry Learning via Distance Learning during the Covid-19 Pandemic.

Tadris: Jurnal Keguruan dan IImu Tarbiyah. v. 5, n. 1, p.155-165. 2020. Disponível em: https://doi.org/10.24042/tadris.v5i1.6346. Acesso em: 12 fev. 2021.

SERAFIN, J. M.; CHABRA, J. Using a Cooperative Hands-On General Chemistry Laboratory Framework for a Virtual General Chemistry Laboratory. Journal of Chemical Education. Disponível em: https://dx.doi.org/10.1021/acs.jchemed.0c00780. Acesso em: 08 fev. 2021.

SHERRER, S. M. A Virtual Laboratory Module Exploring Photosyntesis during Covid-19. Special Issue: IUBMB Education Conference. v. 48, i. 6, p. 659-661, 2020. Disponível em: https://doi.org/10.1002/bmb.21464. Acesso em: 12 fev. 2021.

SYAH, N. et al. Implementation of Practice Learning During the Covid-19 Pandemic. International Journal of recente Technology and Engineering (IJRTE). v. 9, i. 2, p. 1184-1188. 2020. Disponível em: https://doi.org/10.35940/ijte.B4167.079220. Acesso em: 03 fev. 2021.

TERASIC INC. DEO User Manual. Taiwan. April. 2016.

Resumo: A pandemia do novo coronavirus, o Sar-Cov-2, declarada oficialmente em 11 de março de 2020 pela Organização Mundial de Saúde (OMS) fez com que muitas atividades, entre outras, na educação tivessem que ser interrompidas. Para não comprometer o período letivo, muitas atividades precisavam ser retomadas no modo remoto e para isso muitas ferramentas baseadas em Internet foram propostas e usadas com sucesso. O curso de Engenharia Elétrica da Escola Politécnica da Universidade de São Paulo fez suas adaptações, porém o desafio estava nas disciplinas de laboratório. Este trabalho tem por objetivo apresentar as soluções encontradas para a disciplina de Laboratório Digital do Departamento de Engenharia de Computação e Sistemas Digitais (PCS). O resultado observado e manifestado por professores e alunos foi de que a disciplina cumpriu seu papel e com pequena perda de desempenho se comparado ao modo presencial.

Palavras-chave: Ensino remoto, laboratório digital remoto, ferramentas de software. 